RESEARCH ARTICLE

\title{
Behavioral Assessment of Agricultural Post Graduates towards Online Classes
}

Navya Sai Pendyala*, Karthikeyan C, and Shantha Sheela M

Department of Agricultural Extension and Rural Sociology, Tamil Nadu Agricultural University, Coimbatore-641 003

\begin{abstract}
COVID 19 has crippled our country and people on the economy, health, and psychological means. It also majorly affected the students by turning them into a new form of the educational system. Hence, this study deals with the changes in students' behavior during online classes. The survey was conducted through google forms and circulated to a random sample of 112 post-graduate students studying in four different Agricultural Universities in the country, and 90 of them responded. Statistical tools, namely, correlation, mean and standard deviation, were utilized to analyze. Behavioral variables such as accessibility, student interaction, time spent to study and notes taking, had a direct impact on the student skill and the resultant surrounding environment, student interaction had a direct impact on knowledge gain pertaining to online classes.
\end{abstract}

Keywords: COVID 19; Google forms; Online Classes; Students' behavior

\section{INTRODUCTION}

COVID 19 has shaken the world and led to the fall of economies worldwide. Students are one of the major classes of society to be adversely affected due to COVID 19. This pandemic has driven educational institutions to move out of conventional means and adapt online means to keep up with the academic calendar. There were significant developments in technology used for educational purposes, starting from blackboard to PowerPoint. But this pandemic has pushed the limits of these critical technologies and turned the educational teaching system upside down through the introduction of online classes. These online classes are real-time means where teachers and students stay at faraway places and interact virtually through the internet.

Online classes have their own positive and negative aspects. Teachers play a key role in the educational system in India that help control and monitor the behavior of the student in their classes. But in online classes, there is no direct way to monitor the behavior because they are connected virtually, not physically. So, this leads to change in the behavior of students rather than seen in traditional means. One of the positive factors includes that students started utilizing online websites and educational tools after shifting to online classes (Patricia 2020). Due to increased hours of online classes, students started to exhibit social behavior because of long periods of isolation and also mood swings(Swati Agarwal and Jyoti Dewan 2020). This study deals with the noticeable behavior changes in students due to online classes.

\section{MATERIAL AND METHODS}

The study was conducted among the students studying post-graduation in various branches of Agricultural Sciences across four Institutions in the country. They include Tamil Nadu Agricultural University (TNAU), Acharya N.G Ranga Agricultural University (ANGRAU), Banaras Hindu University (BHU), and Sam Higginbottom University of Technology and Sciences (SHAUTS). The survey was conducted by circulating the google forms to a random sample of 112 students but only 90 students responded back. The data collected through google forms contain various fields such as accessibility, punctuality, multi-tasking, surrounding environment, student interaction, self-regulated learning, amount of time to study, notes taken, concentration, skill, and knowledge. Scoring was given to each of the responses. Based on these scores, mean and standard deviation was calculated and were used to divide the respondents into low, medium, and high categories. The correlation was used to establish the relationship between the selected variables and the behavioral aspects of the respondents.

\section{RESULTS AND DISCUSSION}

Responses were received from 90 post-graduate students. Descriptive statistical analysis was conducted and results are shown in Table 1. Among 
these respondents, 53.3 per cent are female and 46.7 per cent are male.

The majority of the respondents have a medium level (73.44\%) of accessibility to attend online classes. This is because there are various areas in the country with poor internet connectivity, even in semi-urban areas. So, this leads to the reduction of students' ability to attend online classes. Nearly three-fourth of the respondents exhibit a medium level $(75.6 \%)$ of punctuality since it was easy to attend online classes because students can attend the classes being at their comfortable place and surrounding. Most of the students exhibit medium level $(66.7 \%)$ of multi-tasking i.e., they often or sometimes involved in multi-tasking while attending online classes because they eventually lose interest and divert to do other activities. Students show a greater multitasking behavior in online classes compared to face-to-face classes. They were mostly involved in sending messages, email, using social networking sites, watching videos, using the internet for purposes unrelated to class, listening to music, and playing video games (Andrew Lepp et al., 2019). A preponderance of the respondents was at a medium level (74.4\%) for having a comfortable environment with proper acoustics and attending in a separate room. This is because most of the students attended classes from their homes in their comfort zone.

Table 1 Profile of PG Students in Agricultural Sciences

$(n=90)$

\begin{tabular}{|c|c|c|c|c|c|c|}
\hline S. No. & Variables & Mean & $\begin{array}{l}\text { Standard } \\
\text { Deviation }\end{array}$ & Categories & Frequency $(\mathrm{N}=90)$ & Percentage \\
\hline \multirow[t]{2}{*}{1} & Gender & - & - & Male & 42 & 46.7 \\
\hline & & & & Female & 48 & 53.3 \\
\hline \multirow[t]{3}{*}{2} & Accessibility & 5.29 & 0.96 & Low $(<4.33)$ & 24 & 26.67 \\
\hline & & & & Medium (4.34-6.1) & 66 & 73.44 \\
\hline & & & & High (>6.2) & Nil & - \\
\hline \multirow[t]{3}{*}{3} & Punctuality & 2.73 & 0.49 & Low $(<2.24)$ & 22 & 24.4 \\
\hline & & & & Medium (2.25-3.21) & 68 & 75.6 \\
\hline & & & & High (>3.22) & Nil & - \\
\hline \multirow[t]{3}{*}{4} & Multi-tasking & 3.02 & 1.02 & $\operatorname{Low}(<2)$ & 23 & 25.5 \\
\hline & & & & Medium (2.1-4.05) & 60 & 66.7 \\
\hline & & & & High (>4.04) & 7 & 7.8 \\
\hline \multirow[t]{3}{*}{5} & Surrounding Environment & 6.80 & 0.92 & Low $(<5.88)$ & 4 & 4.4 \\
\hline & & & & Medium (5.89-7.6) & 67 & 74.4 \\
\hline & & & & High (>7.7) & 19 & 21.1 \\
\hline \multirow[t]{3}{*}{6} & Student Interaction & 2.14 & 0.50 & Low $(<1.6)$ & 6 & 6.7 \\
\hline & & & & Medium (1.7-2.5) & 65 & 72.2 \\
\hline & & & & High (>2.6) & 19 & 21.1 \\
\hline \multirow[t]{3}{*}{7} & Self-Regulated Learning & 1.81 & 0.51 & Low $(<1.2)$ & 22 & 24.2 \\
\hline & & & & Medium (1.3-2.2) & 63 & 70 \\
\hline & & & & High (>2.3) & 5 & 5.6 \\
\hline \multirow[t]{3}{*}{8} & Time spent to Study & 1.94 & 0.68 & Low $(<1.2)$ & 24 & 26.7 \\
\hline & & & & Medium (1.3-2.5) & 47 & 52.2 \\
\hline & & & & High (>2.6) & 19 & 21.1 \\
\hline \multirow[t]{3}{*}{9} & Notes Taken & 2.82 & 0.85 & Low $(<1.9)$ & 6 & 6.7 \\
\hline & & & & Medium (2.0-3.5) & 70 & 77.8 \\
\hline & & & & High (>3.6) & 14 & 15.5 \\
\hline \multirow[t]{3}{*}{10} & Concentration & 4.15 & 0.95 & Low $(<3.2)$ & 21 & 23.3 \\
\hline & & & & Medium (3.3-5.0) & 69 & 76.6 \\
\hline & & & & High (>5.1) & Nil & - \\
\hline \multirow[t]{3}{*}{11} & Skill & 4.06 & 0.84 & Low $(<3.2)$ & 9 & 10 \\
\hline & & & & Medium (3.3-4.8) & 68 & 75.5 \\
\hline & & & & High (>4.9) & 13 & 14.4 \\
\hline \multirow[t]{3}{*}{12} & Knowledge & 5.44 & 0.72 & Low $(<5.02)$ & 11 & 12.2 \\
\hline & & & & Medium (5.03-6.3) & 79 & 87.7 \\
\hline & & & & High (>6.4) & Nil & - \\
\hline
\end{tabular}


About three-quarters (72.2\%) of the respondents occasionally interacted with professors during online classes. This is because most students find it difficult and lack face-to-face communication to interact. The majority of the respondents (70\%) preferred self-regulation for at least a few courses because they don't have the same level of interest to attend various online classes and also, they have a lot of distractions due to lack of monitoring from the professor side. So, they eventually start to self-study rather than listen. About half (52.2\%) of the respondents spend 1-2 hours per day studying or doing assignments during online classes. More than three-fourth $(77.8 \%)$ of the students said that the ease of notes taking is either difficult or moderate during online classes. This is because of decreased interest and a lot of diversions. Most of the respondents $(76.6 \%)$ have acknowledged that they strongly disagree that "students have more concentration in online classes". The majority of the respondents (75.5\%) had a medium level of skill in using online classes i.e., they had basic computer skills required to attend online classes. More than three-fourth (87.7\%) of the respondents had greater knowledge about various mobile applications used in onlineclasses and also use different educational resources to attend online classes.

To establish the relationship of the selected variables to the students' behavior inonline classes, correlation values were calculated and tabulated as shown in table 2.

Table 2: Relationship between the profile of PG students with their extent of skill and knowledge level.

\begin{tabular}{|c|c|c|c|}
\hline \multirow[t]{2}{*}{ S.no } & \multirow[t]{2}{*}{ Variables } & \multicolumn{2}{|c|}{ Correlation (r value) } \\
\hline & & $\operatorname{Skill}\left(\mathrm{Y}_{1}\right)$ & Knowledge $\left(\mathrm{Y}_{2}\right)$ \\
\hline$x_{1}$ & Accessibility & $0.374 * *$ & $0.268 * *$ \\
\hline$x_{2}$ & Punctuality & $0.123^{\mathrm{NS}}$ & $0.029^{\mathrm{NS}}$ \\
\hline$x_{3}$ & Multi-tasking & $0.050^{\mathrm{NS}}$ & $0.067^{\mathrm{NS}}$ \\
\hline$X_{4}$ & Surrounding Environment & $0.174 *$ & $0.157^{\mathrm{NS}}$ \\
\hline$X_{5}$ & Student Interaction & $0.472 * *$ & $0.220 *$ \\
\hline$X_{6}$ & Self-Regulated Learning & -0.125 NS & $-0.008^{N S}$ \\
\hline$x_{7}$ & Time spent to Study & $0.217 * *$ & $0.083^{\mathrm{NS}}$ \\
\hline$x_{8}$ & Notes Taken & $0.295 * *$ & $0.089^{\text {NS }}$ \\
\hline$X_{9}$ & Concentration & $-0.137^{\mathrm{NS}}$ & $-0.137^{\mathrm{NS}}$ \\
\hline
\end{tabular}

**Significant at the 0.01 level *Significant at the 0.05 level NS- Non-significant
From table 2 it can be derived that, out of nine independent variables, four variables such as $X_{1}, X_{5}, X_{7}$, and $X_{8}$ have a positive significant relationship with the dependent variable skill $\left(Y_{1}\right)$ at a 5 per cent level of probability and variable $X_{4}$ has a positive and significant relationship to the dependent variable skill (Y1) at a 1 per cent level of probability. Variables such as accessibility (X1) have a positive and significant relationship to the dependent variable, knowledge (Y2) at a 5 per cent level of probability and variable student interaction (X5) has a positive and significant relationship to the dependent variable knowledge (Y2) at a 1 per cent level of probability.

\section{CONCLUSION}

Control and monitoring have declined in online education, thereby giving tremendous freedom to the students to act as they wish. This made the students divert from the original path they had been following before the pandemic. Student behavioral components such as accessibility, student interaction, time taken to study, notes taking, and surrounding environment directly impacted skill and knowledge in online classes. Some students have shown difficulty in attending offline classes after a prolonged period of attending online classes. Hence, care should be ensured from the side of professors to do some kind of monitoring such as the sudden raising of questions to random students to know the attentiveness of the student during the class and along with it, the classes need be made interactive to ensure classroom behavior of the student. Student accountability is important to present proper behavior irrespective of the mode of teaching. In online education, students' selfreflection is vitally significant (Chakraborty et al., 2020). The student should also be responsible to work as if it was in a traditional classroom.

\section{Ethics statement}

No specific permits were required for the described field studies because no human or animal subjects were involved in this research.

\section{Consent for publication}

All the authors agreed to publish the content.

\section{Competing interests}

The Author(s) declare(s) that there is no conflict of interest.

\section{Data availability}

All the data of this manuscript are included in the MS. No separate external data source is required. If anything is required from the MS, certainly, this will be extended by communicating with the corresponding author through corresponding official mail; navyasai567@gmail.com 


\section{REFERENCES}

Agarwal Swathi and Jyothi Dewan. 2020. An analysis of the effectiveness of online learning in colleges of Uttar Pradesh during the Covid-19 Lockdown. J. Xi'an Univ. Archit. amp; Technol. 9(5): 2957-2963.

A. Patricia Aguilera-Hermida. 2020. College students Use and acceptance of emergency online Learning Due to COVID-19. Int. J. Educ. Res. 1: 100011
Chakraborty Pinaki, Prabhat Mittal, Manu Sheel Gupta, Savita Yadav, and Anshika Arora. 2020. Opinion of students on online education during the COVID-19 pandemic. Hum. Behav. Emerg. Technol. 3(3): 1-9.

Leep Andrew, Jacob, E., Barkley, Aryn, C., Karpinski, and Shweta Singh. 2019. College Students' Multitasking Behavior in Online Versus Face-toFace Courses. SAGE Open. 9(1): 1-9. 